\title{
Intracolonic Administration of Vancomycin in Intensive Care Unit Patients with Severe Clostridium Difficile Colitis
}

\author{
Alex Teixeira ${ }^{1}$, Kartikeya Tripathi ${ }^{2}$, Yesenia Greeff ${ }^{3}$, Omar Sorour ${ }^{4}$, Paul Mccallion ${ }^{5}$, Garrison Davis ${ }^{6}$, \\ Khaled Sorour ${ }^{7}$ \\ 1. Gastroenterology and Hepatology, Signature Healthcare Brockton Hospital, Brockton, USA 2. Gastroenterology, \\ University of Massachusetts Medical School Baystate, Springfield, USA 3. Gastroenterology and Hepatology, University \\ of Massachusetts Medical School Baystate, Springfield, USA 4. Internal Medicine, University of Massachusetts, \\ Worcester, USA 5. Anesthesiology, Signature Healthcare Brockton Hospital, Brockton, USA 6. Internal Medicine, \\ Signature Healthcare Brockton Hospital, Brockton, USA 7. Critical Care Medicine, Signature Healthcare Brockton \\ Hospital, Brockton, USA
}

Corresponding author: Kartikeya Tripathi, dr.kartik1112@gmail.com

\begin{abstract}
Background: Clostridium difficile infection (CDI) is a major cause of antibiotic-associated diarrhea worldwide. The incidence of sepsis has been shown to be increasing due to severe or fulminant colitis. Oral vancomycin is the treatment of choice for CDI, but it is often ineffective in patients in the intensive care unit (ICU) due to poor intestinal motility. We present a review of eight cases with severe to fulminant CDI treated with adjunctive intracolonic vancomycin (ICV) administration.
\end{abstract}

Methods: A retrospective chart review identified patients in sepsis with severe colitis and positive Clostridium difficile toxin A or B. Patients who had failed standard therapy for CDI were given adjunctive ICV through an enteric tube, which was inserted via colonoscopy. To indicate the severity of patients, the patients selected had required vasopressor support.

Results: Eight patients (37.5\% females) received this adjunctive treatment; the mean age was 73.25 . The average Acute Physiology and Chronic Health Evaluation (APACHE) 2 score at the time of the procedure was 39. The median length of stay was 5.5 days, with in-hospital mortality of $37.5 \%$ and an average time to death of 1.33 days from the day of colonoscopy.

Conclusion: Colonoscopic decompression and administration of vancomycin for fulminant CDI using an enteric tube can have favorable outcomes in severely ill patients whose surgical options carry a high risk of mortality. Further larger randomized controlled trials are needed to evaluate its efficacy.

Review began 10/14/2020 Review ended 11/08/2020 Published 11/19/2020

() Copyright 2020 Teixeira et al. This is an open access article distributed under the terms of the Creative Commons Attribution License CC-BY 4.0., which permits unrestricted use, distribution, and reproduction in any medium, provided the original author and source are credited.
Categories: Internal Medicine, Gastroenterology, Infectious Disease

Keywords: clostridium difficile infection, sepsis, colitis, vancomycin, colonoscopy, intracolonic vancomycin

\section{Introduction}

Clostridium difficile infection (CDI) is a major cause of antibiotic-associated diarrhea worldwide, and the incidence of fulminant colitis is on the rise [1,2]. CDI is responsible for approximately 30,000 deaths, leading to almost $\$ 5$ billion in excess health care costs associated with acute care hospitalizations in the United States [3]. Of patients with CDI, 3\%-8\% develop fulminant colitis with a mortality rate of up to $57 \%$ [4,5]. Oral vancomycin therapy is the treatment of choice for Clostridium difficile colitis. However, it has shown to be ineffective in fulminant CDI, especially for patients in the intensive care unit (ICU), as poor intestinal motility prevents achieving adequate therapeutic concentrations of the antibiotic [6,7]. Concomitant use of rectal vancomycin with retention enemas fail to deliver proximally to the splenic flexure of the colon [8]. Effective treatment outcomes with intracolonic administration of vancomycin in critically ill patients with pseudomembranous colitis was first described as early as in 1993, but its use has been limited thus far due to risks of perforation of inflamed colon [9]. We present a review of eight cases where using intracolonic vancomycin (ICV) in severely ill patients in the ICU with CDI had preferable outcomes when compared to surgery.

\section{Materials And Methods}

We did a retrospective chart review from January 30, 2010 to December 31, 2012 for patients admitted in the ICU with CDI and septic shock. The study was approved by the Institutional Review Board. The diagnosis was based on the International Classification of Diseases, 9th revision (ICD-9) diagnosis codes from the electronic medical records at the Brockton hospital, Brockton, Massachusetts, USA. The case definition used was symptomatic diarrhea positive for Clostridium difficile toxins A and B in stool determined by enzyme immunoassay (EIA) or with endoscopic findings consistent with pseudomembranous colitis. The cases were de-identified using their account number and were given a unique alpha-numeric number. Data was captured on Microsoft Excel, which recorded patient demographics, clinical characteristics, hospital course, and treatment details. 


\section{Cureus}

The patients selected received adjunctive intracolonic administration with vancomycin. The severity of the disease was assessed clinically. Patients selected for the procedure were those who required high dose of vasopressors - i.e. over $20 \mathrm{mcg} / \mathrm{min}$ of norepinephrine and on vasopressin per protocol. All selected patients had failed standard therapy for CDI, including oral and rectal vancomycin, intravenous metronidazole and/or oral rifaximin. In addition, they received standard fluid and pressor management based on a standardized early goal-directed therapy-based protocol. A long enteric tube was inserted via colonoscopy and secured at the level of the cecum. Adjunctive ICV at a dose of 2 grams twice a day was delivered which was prepared in the hospital pharmacy.

In addition to standard demographic information, other forms of data collected included date of hospital admission, date of discharge, date of colonoscopy, length of hospital stay, quantification of diarrhea on admission, white blood cell (WBC) count on the day of colonoscopy, average WBC count, lactate on the day of colonoscopy, average lactate, Acute Physiology and Chronic Health Evaluation (APACHE) 2 score,

colonoscopic findings and time to death. The primary outcomes were in-hospital mortality, resolution of shock, or resolution of leukocytosis. The secondary outcomes were the median length of stay, time to death, or discharge.

\section{Results}

Eight patients received the adjunctive treatment and had either Clostridium difficile stool toxin positive or endoscopic findings of pseudomembranous colitis (Tables 1-2). The mean age of the included cases was 73.3 (SD \pm 11.9 ) with $37.5 \%$ females. The median length of stay in the hospital was 5.5 days with a range of 3 to 27 days. All eight patients had pseudomembranous colitis at the time of colonoscopy; one had necrosis. Average WBC count was $28.2( \pm 17.4)$ and an average lactate level of $3.6( \pm 2)$. The mean APACHE2 score at the time of procedure was 39 , with in-hospital mortality among the patients who received adjunctive treatment of $37.5 \%$. Their average time to death was 1.3 days from the day of the colonoscopy. None of the eight patients had known immediate complications from the procedure, including perforation. 


\section{Cureus}

\begin{tabular}{|c|c|c|c|c|c|c|c|c|}
\hline Variable & Patient A1 & Patient B1 & $\begin{array}{l}\text { Patient } \\
\text { C1 }\end{array}$ & Patient D1 & Patient E1 & Patient F1 & Patient G1 & Patient H1 \\
\hline Age & 86 & 68 & 77 & 57 & 53 & 80 & 87 & 78 \\
\hline Gender & Male & Male & Female & Male & Female & Female & Male & Male \\
\hline $\begin{array}{l}\text { Date of } \\
\text { admission }\end{array}$ & 08/27/2012 & 05/26/12 & 01/25/12 & 05/09/11 & 05/07/11 & 04/26/11 & 10/06/10 & 09/19/10 \\
\hline $\begin{array}{l}\text { Date of } \\
\text { discharge* }\end{array}$ & 09/05/12 & 06/01/12 & 02/01/12 & 05/10/11 & 05/13/11 & 05/06/11 & 10/09/10 & 10/26/10 \\
\hline $\begin{array}{l}\text { Date of } \\
\text { colonoscopy }\end{array}$ & 09/05/12 & 05/29/12 & $01 / 26 / 12$ & 05/10/11 & 05/09/11 & 04/27/11 & 10/07/10 & 10/13/10 \\
\hline $\begin{array}{l}\text { Length of } \\
\text { hospital stay }\end{array}$ & 8 & 5 & 6 & 2 & 5 & 9 & 3 & 27 \\
\hline $\begin{array}{l}\text { Diarrhea on } \\
\text { admission }\end{array}$ & No & Yes & Yes & Yes & Yes & Yes & Yes & Yes \\
\hline $\begin{array}{l}\text { WBC count } \\
\text { on day of } \\
\text { colonoscopy }\end{array}$ & 45.8 & 20.0 & 14.5 & 38.3 & 19.4 & 53.9 & 32.0 & 1.7 \\
\hline $\begin{array}{l}\text { Lactate on } \\
\text { the day of } \\
\text { colonoscopy }\end{array}$ & 2.0 & 1.7 & 4.2 & $>12.2$ & 1.6 & 4.0 & 1.4 & 1.5 \\
\hline $\begin{array}{l}\text { APACHE2 } \\
\text { score }\end{array}$ & 41 & 32 & 40 & 35 & 29 & 49 & 45 & 41 \\
\hline $\begin{array}{l}\text { Colonoscopy } \\
\text { findings }\end{array}$ & pseudomembrane & pseudomembrane & $\begin{array}{l}\text { Ischemic } \\
\text { colitis }\end{array}$ & pseudomembrane & pseudomembrane & pseudomembrane & pseudomembrane & $\begin{array}{l}\text { Pseudomembre } \\
\text { necrosis }\end{array}$ \\
\hline $\begin{array}{l}\text { In hospital } \\
\text { death }\end{array}$ & Yes & No & No & Yes & No & No & Yes & No \\
\hline $\begin{array}{l}\text { Date of } \\
\text { death }\end{array}$ & 09/05/12 & - & - & 05/10/11 & - & - & 10/09/10 & - \\
\hline $\begin{array}{l}\text { Number of } \\
\text { days- } \\
\text { Admission to } \\
\text { colonoscopy }\end{array}$ & 8 & 2 & 2 & 2 & 1 & 2 & 2 & 18 \\
\hline $\begin{array}{l}\text { Number of } \\
\text { days- } \\
\text { Colonoscopy } \\
\text { to death }\end{array}$ & 1 & - & - & 1 & - & - & 2 & - \\
\hline
\end{tabular}

TABLE 1: Demographics, Clinical Characteristics of the Patients, Hospital Course and Treatment Details

WBC: white blood cell; APACHE2: Acute Physiology and Chronic Health Evaluation 2 score. 


\begin{tabular}{|l|l|}
\hline Variable & Result \\
\hline Average Age (SD) & $73.25(11.91)$ \\
\hline Males & $62.5 \%$ \\
\hline Females & $37.5 \%$ \\
Median Length of stay (Range) & $5.5(3$ to 27) \\
Average WBC count & 28.2 \\
Average lactate & 3.6 \\
Median lactate & 1.9 \\
\hline Average APACHE2 score & 39 \\
In hospital mortality & $37.5 \%$ \\
Average time to death after colonoscopy & 1.33 \\
\hline
\end{tabular}

\section{TABLE 2: Results}

WBC: white blood cell; APACHE2: Acute Physiology and Chronic Health Evaluation 2 score.

\section{Discussion}

CDI was first reported in 1978, and its incidence, recurrence, and virulence are on the rise [10]. It is established that CDI increases the cost of hospitalizations and raises the incidence of readmissions. It was reported in a study in 2016, that the total cost attributable to CDI management in the United States was nearly $\$ 6.3$ billion. Treating CDI adds about $\$ 7,285$ in hospital costs per patient, which does not include costs of readmissions [11]. The treatment and control of CDI has been a challenge and has not improved in the last several years. As per the Infectious Diseases Society of America (IDSA) and Society for Healthcare Epidemiology of America (SHEA) guidelines in 2018, high dose oral vancomycin in addition to retention rectal enema with or without intravenous metronidazole is recommended for fulminant CDI [12,13]. Despite these measures, it is frequently difficult to bring it to resolution, as ultimately it leads to colectomy and many times, death [14].

Due to lack of data from randomized controlled trials and the risks associated with the procedure, intracolonic use of vancomycin is not the standard of care in patients refractory to standard treatment. The only available literature is a retrospective case series, which makes it difficult to assess complications, recurrence, and success of treatment to formulate guidelines [15].

Interestingly, the mortality achieved by surgical intervention in these patients is comparable with this procedure. The mortality with surgery is similar or sometimes higher: on vasopressor support in sepsis with CDI, mortality ranges from 32\%-57\% after colectomy [16,17]. We propose that adjunctive use of ICV could in certain cases obviate the need for surgery and salvage the colon, especially elderly patients with multiple comorbidities who are not surgical candidates. Of the five patients who were older than 70 years of age, the presence of hemodynamic instability and leukocytosis or leukopenia predict a mortality rate of $57.1 \%$ with surgery, whereas the mortality rate in our series for those patients was $40 \%$ [17].

Unfortunately, the latest guidelines by IDSA and SHEA do not mention the use of adjunctive ICV, presumably due to limited scholarly work and retrospective data available $[6,12,18]$. As per these guidelines, segmental or subtotal colectomy or loop ileostomy with antegrade vancomycin lavage is usually the next course in the management. However, the earlier guidelines noted its use for fulminant CDI, but did not necessitate or elaborate a clinical criterion for patient selection. It is important to ascertain that most of these patients, especially in the ICU, have other co-morbidities limiting their surgical options and exponentially increase their risk of postoperative morbidity and mortality. It would be reasonable to mention that there are not any surgical guidelines for patient selection, and more often than not, the decision is made clinically. Adjunctive use of ICV could be an alternative in these patients to avoid surgery or be attempted when surgery is not feasible given other risks [19].

There are several strengths to this review. We emphasize the use of ICV could be an alternative to surgery in patients, especially in the ICU. It is evident from the review that early instillation of ICV could decrease mortality. It could be done as early as on day two. Mortality was directly proportional to the delay in the procedure. This procedure was done in a community hospital without any reported complication of the procedure itself, including perforation.

This review has some limitations. As with all retrospective observational study, data was retrieved from the existing records, which could have missing information. However, given the design of the study and data 
collection, the likelihood of missing data was minimal. Follow-up records were not obtained when the patient was discharged from the hospital. It would be useful to follow these patients and document resolution or assess for recurrence. Therefore, the disease severity and intervention with ICV of these patients may have been skewed. We did not have a control group, as these patients were too sick for a placebo-controlled trial, and it would be unethical not to intervene. Use of ICV can probably be compared to patients with APACHE2 scores of 39, however, whose expected mortality is $82 \%$ percent. Finally, the small number of patients in the review and a single-center data point to the need for large randomized control trials to compare the efficacy of ICV to surgery or conservative options.

\section{Conclusions}

The incidence of CDI has been increasing and associated readmissions, in turn, increase healthcare expenses. Severe sepsis with CDI, leads to inability to perform further intervention since these patients are not surgical candidates for colectomy. Ultimately, the mortality of these patients is increased in the absence of intervention. When other modalities fail, surgery is not an option and goals of care are discussed, we suggest that colonoscopic assisted colonic/enteric tube administration of vancomycin could be used in these patients.

\section{Additional Information \\ Disclosures}

Human subjects: Consent was obtained by all participants in this study. IRB issued approval 1120011. Animal subjects: All authors have confirmed that this study did not involve animal subjects or tissue. Conflicts of interest: In compliance with the ICMJE uniform disclosure form, all authors declare the following: Payment/services info: All authors have declared that no financial support was received from any organization for the submitted work. Financial relationships: All authors have declared that they have no financial relationships at present or within the previous three years with any organizations that might have an interest in the submitted work. Other relationships: All authors have declared that there are no other relationships or activities that could appear to have influenced the submitted work.

\section{Acknowledgements}

Joel Popkin, MD jpopkin6244@gmail.com

\section{References}

1. Surawicz CM, Brandt LJ, Binion DG, et al.: Guidelines for diagnosis, treatment, and prevention of Clostridium difficile infections. Am J Gastroenterol. 2013, 108:478-498. 10.1038/ajg.2013.4

2. Akamine CM, Ing MB, Jackson CS, Loo LK: The efficacy of intracolonic vancomycin for severe Clostridium difficile colitis: a case series. BMC Infect Dis. 2016, 16:316. 10.1186/s12879-016-1657-1

3. Lessa FC, Mu Y, Bamberg WM, et al.: Burden of Clostridium difficile infection in the United States . N Engl J Med. 2015, 372:2369-2370. 10.1056/NEJMc1505190

4. Adams SD, Mercer DW: Fulminant Clostridium difficile colitis. Curr Opin Crit Care. 2007, 13:450-455. 10.1097/MCC.0b013e3282638879

5. Sailhamer EA, Carson K, Chang Y: Fulminant Clostridium difficile colitis: patterns of care and predictors of mortality. Arch Surg. 2009, 144:433-439. 10.1001/archsurg.2009.51

6. Apisarnthanarak A, Razavi B, Mundy LM: Adjunctive intracolonic vancomycin for severe Clostridium difficile colitis: case series and review of the literature. Clin Infect Dis. 2002, 35:690-696. 10.1086/342334

7. Riddle DJ, Dubberke ER: Clostridium difficile Infection in the intensive care unit. Infect Dis Clin North Am. 2009, 23:727-743. 10.1016/j.idc.2009.04.011

8. Shen EP, Surawicz CM: Current treatment options for severe Clostridium difficile-associated disease . Gastroenterol Hepatol (N Y). 2008, 4:134-139.

9. Pasic M, Jost R, Carrel T, Von Segesser L, Turina M: Intracolonic vancomycin for pseudomembranous colitis. N Engl J Med. 1993, 329:583. 10.1056/NEJM199308193290819

10. Cheung SW, Li KK: Fulminant pseudomembranous colitis presenting as sigmoid stricture and severe polyposis with clinical response to intracolonic vancomycin. Case Rep Med. 2016, 10.1155/2016/4609824

11. Zhang S, Palazuelos-Munoz S, Balsells EM, Nair H, Chit A, Kyaw MH: Cost of hospital management of Clostridium difficile infection in United States-a meta-analysis and modelling study. BMC Infect Dis. 2016, 16:447. 10.1186/s12879-016-1786-6

12. McDonald LC, Gerding DN, Johnson S, et al.: Clinical practice guidelines for Clostridium difficile infection in adults and children: 2017 update by the Infectious Diseases Society of America (IDSA) and Society for Healthcare Epidemiology of America (SHEA). Clin Infect Dis. 2018, 66:987-994. 10.1093/cid/ciy149

13. Rokas KEE, Johnson JW, Beardsley JR, Ohl CA, Luther VP, Williamson JC: Addition of intravenous metronidazole to oral vancomycin is associated with improved mortality in critically ill patients with Clostridium difficile infection. Clin Infect Dis. 2015, 61:934-941. 10.1093/cid/civ409

14. Gash K, Brown E, Pullyblank A: Emergency subtotal colectomy for fulminant Clostridium difficile colitis - is a surgical solution considered for all patients?. Ann R Coll Surg Engl. 2010, 92:56-60. 10.1308/003588410X12518836439164

15. Shetler K, Nieuwenhuis R, Wren SM, Triadafilopoulos G: Decompressive colonoscopy with intracolonic vancomycin administration for the treatment of severe pseudomembranous colitis. Surg Endosc. 2001, 15:653-659. 10.1007/s004640080104

16. Seltman AK: Surgical management of Clostridium difficile colitis. Clin Colon Rectal Surg. 2012, 25:204-209. 10.1055/s-0032-1329390

17. Dallal RM, Harbrecht BG, Boujoukas AJ, Sirio CA, Farkas LM, Lee KK, Simmons RL: Fulminant Clostridium difficile: an underappreciated and increasing cause of death and complications. Ann Surg. 2002, 235:363- 


\section{Cureus}

372. 10.1097/00000658-200203000-00008

18. Malamood M, Nellis E, Ehrlich AC, Friedenberg FK: Vancomycin enemas as adjunctive therapy for Clostridium difficile infection. J Clin Med Res. 2015, 7:422-427. 10.14740/jocmr2117w

19. Alex T, Tripathi K, Reisch-Neyman Y, Sorour O, McCallion P, Davis G, Sorour K: Intracolonic administration of vancomycin via cecal tube in intensive care unit patients with fulminant Clostridium difficile colitis. Am J Gastroenterol. 2018, 113:S1572. 